Instituto Internacional de Investigación y Desarrollo Tecnológico Educativo INDTEC, C.A.

DOI: https://doi.org/10.29394/scientific.issn.2542-2987.2017.2.3.11.209-225

OAI-PMH: http://www.indteca.com/ojs/index.php/Revista Scientific/oai

\title{
Desarrollar Acciones Didácticas para la Conservación de los Petroglifos del Municipio Antonio José de Sucre Barinas 2016
}

Autora: Livia Elizabeth Arista Díaz

Universidad Pedagógica Experimental Libertador, UPEL

livieliza@hotmail.com

Barinas, Venezuela

\section{Resumen}

El presente trabajo de investigación está centrado en el Desarrollo de Acciones Didácticas para la Conservación de los Petroglifos en el Municipio Antonio José de Sucre Barinas 2016. La metodología es de naturaleza cualitativa en la que se destaca la etnografía como vía para acceder a las características particulares del tema de estudio, se abordara desde las perspectivas de tres informantes claves comprendidos en un vecino cercano, un guía turístico y un cronista del municipio cercanos al espacio geográfico en donde se ubican los petroglifos; para ello será necesario recoger la información a través de la aplicación de la técnica de la entrevista empleando el cuestionario como instrumento de recolección de datos. En ese sentido, con este estudio se busca propiciar acciones consientes acerca del cuidado y respeto a los grabados y patrimonio ancestrales originarios de las culturas autóctonas de la región preservando así las aéreas físicas para fomentar el turismo y la recreación en estos espacios.

Palabras clave: acciones didácticas; conservación; petroglifos. 


\title{
Develop Didactic Actions for the Conservation of the Petroglyphs of the Municipality Antonio José de Sucre Barinas 2016
}

\begin{abstract}
This esearch work is focused on the development of training actions for the conservation of the petroglyphs in the municipality Antonio José de Sucre Barinas 2016. The methodology is qualitative in nature in which stands the Ethnography as via access to the particular characteristics of the subject of study, are addressed from the perspectives of three key informants included a close neighbor, a tour guide and a chronicler of the municipality near the geographical space where the petroglyphs are located; This will require to collect information through the application of the technique of the interview using the questionnaire as an instrument of data collection. In that sense, this study seeks to promote actions aware about the care and respect for ancestral engravings and heritage originating in the native cultures of the region, thus preserving the air physical to encourage tourism and recreation in these areas.
\end{abstract}

Keywords: didactic activities; conservation; petroglyphs. 


\section{Introducción}

Desde siempre el hombre ha tenido la curiosidad imperiosa de saber más de sus orígenes de dónde venimos y hacia dónde vamos, pero para que el individuo pueda conocer sus raíces es ineludible primeramente adentrarse en su pasado comunicarse en su propia identidad y conjunto cultural, es por ello que para entender mejor lo que somos tenemos que saber primero lo que fuimos, posiblemente al comienzo de todos los tiempos en el origen mismo de las culturas primitivas estaba escondido eso que fuimos en el sentido más profundo de nuestra naturaleza humana.

Cuando el mundo globalizado de hoy anuncia la realidad inmediata como una sociedad universal sin barreras ni diferencias étnicas y religiones es cuando más la humanidad debe sujetarse a su propia cultura, investigándose en ella y aprendiendo a valorar sus orígenes y territorio, es decir, cuando el espacio cobra significados subjetivos para los hombres y mujeres que los habitan.

Por ende, Bonell (2005), expresa en su trabajo de investigación titulado: Los Petroglifos como formas de comunicación simbólica reportaje investigativo que: "a través de la cultura el ser humano se expresa, cuestiona sus realizaciones, indaga en nuevos significados y funda obras que le transcienden los petroglifos son una de las creaciones culturales más preeminentes del hombre" (pág. 9).

En América Latina los aborígenes de las distintas etnias que poblaron y aún hoy día pueblan los territorios en su afán por comprender las incógnitas del universo se dedicaron a plasmar sus inquietudes e ideas a través de trazados y grabados en rocas en estado natural. Los petroglifos es la muestra más antigua de este tipo de manifestación. Aunque es una de las últimas expresiones artísticas que ha ocupado el tiempo de los investigadores, también es cierto que implica la atención de diversas disciplinas: arqueología, 
etnografía, sociología, ecología, historia, lingüística, además los artistas y teóricos del arte.

Esto nos hace testigos sobre cómo la sociedad o la cultura se relacionan con su ambiente, el patrimonio histórico cultural involucra distintas instituciones sociales, que permiten identificar a los ciudadanos con su patrimonio, aunque cada sociedad rescata el pasado de distintas maneras. Es importante el conocimiento de los petroglifos debido a que permite a las personas identificarse y rescatar el sentido de pertenencia por estos espacios, de igual forma estimular la memoria histórica que se obtiene del entorno, el valor formativo que tiene el patrimonio, para poder comprender las raíces culturales del medio social que lo rodea.

Desde el punto vista de las ciencias sociales, el patrimonio histórico cultural ha tenido un impacto en la sociedad a través de los años, según Tylor (1975):

La cultura o civilización, en sentido etnográfico amplio, es aquel todo complejo que incluye el conocimiento, las creencias, el arte, la moral, el derecho, las costumbres y cualesquiera otros hábitos y capacidades adquiridos por el hombre en cuanto miembro de la sociedad (pág. 29).

Dentro de este contexto los petroglifos, nos lleva a un conjunto de elementos Geohistóricos que permiten al hombre identificarse con su ambiente, valorar los aspectos culturales, interpretar todo lo que está a su alrededor, tener conocimiento de los hallazgos del patrimonio histórico, como valor simbólico, determinado por medio de la historia, cada uno de estos conjuntos llevan a realizar actividades en pro de preservarlos, difundirlos y definirlos, aunque estos bienes reunidos por la historia no pertenecen realmente a todos, aunque así lo parezca, existe en gran medida una desmotivación y deterioro de los recursos culturales causados por el hombre. 
Fernández y Guzmán (2013) señalan que: "siempre aparece como más importante el interés económico de maximizar los beneficios, que la adopción de medidas concretas de salvaguarda de los diversos componentes que integran el patrimonio histórico-cultural". Considerando esto el desarrollo sustentable propone estrategias diversificadas que permitan mejorar la realidad social, política, económica y ambiental específica de cada lugar. Así el turismo, como uno de sus ejes de acción, propuesto para algunas comunidades, puede preservar o revalorizar elementos patrimoniales (pág. 1).

Es importante destacar el sentido de pertenencia que posee los petroglifos en la formación ciudadana ya que permite identificarse y valorar la nación a la que pertenece. Es preciso educar para salvar y constituir nuevos valores sobre la importancia y normas de respeto, porque quienes cuidan su identidad cultural son protectores y buenos directores de cuyos bienes se enseñan, cuando la enseñanza se vuelve prospera la cultura se hace sostenible.

En Venezuela, cuenta con una importante representación de lugares que formaron parte de los acontecimientos de la lucha por la independencia, como son sus museos, teatros, Iglesias y centros culturales, innumerables tradiciones y monumentos naturales, así como también una gran variedad de petroglifos sumado a un extraordinario aporte lingüístico, arquitectónico, de artes decorativas, pintura, orfebrería y mobiliario, Infopedia Barinas (2007a), destaca que:

La cantidad de rocas con petroglifos ubicados hasta el momento y la variedad de grabados y figuras, constituyen un verdadero reto para el estudioso del arte rupestre, de la región, y quizás del Norte de Sudamérica, las cuales tienen su inicio como circuito arqueológico en las faldas de la Montaña de Peña Viva, cerca de las nacientes del Río Bum-Búm (pág. 1). 
Es notorio expresa que el censo del patrimonio cultural venezolano es una acción y actividad que ha proporcionado por muchos años el reconocimiento y registro, a lo largo y ancho del territorio nacional, de todas aquellas manifestaciones culturales que caracterizan al pueblo venezolano y tienen significación.

Uno de los estados que posee gran variedad de petroglifos es Barinas, específicamente en la población de Bum-Bum, Municipio Antonio José de Sucre son particulares por su ubicación además despiertan la capacidad simbólica de los seres humanos en busca de su interpretación, por otra parte es necesario despertar el interés investigativo en cuanto a este arte, que es orgullo para el país y nos ayuda a aumentar nuestra identidad e importancia cultural que se mantiene viva.

Estas estaciones se mantienen ahí, como testimonio de nuestro valioso pasado cultural, reclamando con justicia su protección lo cual se hace necesario la convocatoria de iniciar el estudio, rescate y conservación de todo aquello que signifique o contenga alguna relación con las culturas aborígenes ya que dichos testimonios constituyen la herencia histórica, no solamente de los Barineses, sino que son propiedad del universo y por consiguiente de la humanidad.

Debido a todas estas razones se considera necesario indagar e investigar sobre el grave peligro para la conservación de los petroglifos. Luego de haber soportado el paso del tiempo y las inclemencias del clima, ahora deben lidiar con la incultura de algunas personas. De acuerdo con los entendidos, en este sitio arqueológico se ubica una de las más grandes aglomeraciones de arte rupestre del estado. Sin embargo, este importante patrimonio ha sido dañado a lo largo de los años y podría correr el riesgo de desaparecer.

Es por ello que se deben realizar Acciones Didácticas para Concienciar los Pobladores de Bum-Bum sobre la Conservación del Área donde se 
Encuentran Petroglifos Ubicados en el Municipio Antonio José de Sucre del Estado Barinas, por ende, es necesario servir de apoyo en cuanto al conocimiento, la investigación, la identidad social y la cultural, además es de suma importancia para la conservación, pues son bienes heredados a través de la historia, permitiendo así una interacción con la sociedad y una valorización de dichos lugares, donde refuerzan la identidad.

Por lo anteriormente expuesto la autora se plantean las siguientes interrogantes:

¿Cuál es el conocimiento que poseen los pobladores de Bum-Bum sobre la Conservación del Área donde se Encuentran los Petroglifos en el Municipio Antonio José de Sucre del Estado Barinas?

¿Qué valores y actitudes pueden fomentarse en los pobladores de Bum-Bum incide en la Conservación del área donde se encuentran los petroglifos ubicados en el Municipio Antonio José de Sucre del Estado Barinas?

¿Cuál sería la didáctica para concienciar a los pobladores de Bum- Bum sobre la conservación de los petroglifos de ubicados en el Municipio Antonio José de Sucre del Estado Barinas?

\section{Petroglifos en Venezuela}

Criollo y Rojas (1995): con el objeto de investigar y difundir aspectos, enigmas aún no suficientemente concluidos sobre la naturaleza, su gente, su arte, la cultura, la ciencia. Parte de esta investigación les ha permitido recolectar un aproximado de más de 470 piezas que datan la prehistoria de Venezuela y un aproximado de 600 localizados entre Colombia, Perú y las Islas del Caribe, empleando sus propios recursos. Este matrimonio de investigadores ha tomado la misión de difundir masivamente esas piezas, en réplicas diseñando cristales y otras técnicas que puedan acercar al hombre a la reflexión del enigma del ser humano y a las constantes en su evolución. 
Los Petroglifos son signos grabados en piedra en época prehistórica, en Venezuela se han hallado 470 ejemplares y se calculan que están entre los 3.000 y 5.000 años A.C. Entre los instrumentos que se utilizaron en el tallado están la abrasión o frotamiento con piedras complementadas con el uso de arena, agua y conchas marinas y la percusión lítica, llevada a cabo por medio de cinceles y martillos líticos. También se empleaba la sabia silicolítica de algunas plantas, aplicándola a la roca para desintegrar la superficie que se quería grabar.

El Petroglifo más grande que se ha encontrado en nuestro país, es la "La Rueda del Indio" en Chirgua, Estado Carabobo, en el patio de la hacienda Caria prima.

\subsection{Petroglifos en Bum-Bum}

Dentro de la configuración geográfica del estado Barinas, se encuentra una zona privilegiada por la naturaleza y llena de encantos naturales conocida como Pie de Monte Andino. Allí se ubica el maravilloso pueblito de Bum-Bum, a las orillas de la troncal cinco, vía San Cristóbal Barinas, perteneciente al Municipio Antonio José de Sucre, Bum-Bum, pueblo que por su nombre llama a toda la atención, y que según los cronistas se deriva de los sonidos guturales emitidos por los indígenas, cuando navegaban por el río que se conoce con el mismo nombre y que nace en el páramo de San Pedro del Estado Mérida.

Según Infopedia Barinas (2007b): menciona que el cronista Fray Pedro Simón, señalo que estas tierras estuvieron habitadas por los indígenas Jiraharas y Caquetíos, aunque algunas versiones señalan que el verdadero nombre de estas tribus era Giros, dentro de las sabanas de Bum-Bum encontramos vigilante y majestuosa lo que los lugareños conocen como Peña Viva, un inmenso cerro peñascoso cubierto por abundante vegetación, y que según algunos era motivo de adoración por los indígenas que habitaban la zona. 
Su denominación de Peña Viva se debe a varios mitos y leyendas que han pasado de generación en generación, las cuales algunas dicen que esta peña se mueve y quien quiera explorarla se pierde en sus alrededores sin lograr llegar a ella, otras leyendas cuentan que en el interior de la peña salen sonidos extraños y que todavía viven en ellas indígenas de muy baja estatura, algunos habitantes de la zona dicen haberlos visto, y que en las noches se oyen sonidos de tambores y otros ecos percutores.

Una persona concienciada ecológicamente sería aquella proclive a desarrollar un amplio abanico de comportamientos pros ambientales, así como a poseer determinados valores y actitudes que distintas teorías han asociado a los mismos. La conciencia ambiental así entendida, equivaldría a lo que se puede considerar la dimensión actitudinal (o psicológica) del comportamiento pro ambiental.

Al definir el concepto de conciencia ambiental se pretende integrar algunas de las principales aportaciones realizadas desde diversos enfoques teóricos al estudio de este fenómeno. Bajo estos parámetros y con una visión focalizada, se persigue integrar las teorías de la preocupación ambiental, más habituales en las aproximaciones sociológicas y las teorías del comportamiento ambiental que se encontraron en la psicología (social) ambiental.

La cultura, según la define Tylor (ídem): "es un sistema de concepciones expresadas en formas simbólicas por medio de las cuales la gente se comunica, perpetúa y desarrolla su conocimiento sobre las actitudes hacia la vida" (pág. 5).

Más recientemente la UNESCO (2011): establece que, puede considerarse actualmente como el conjunto de los rasgos distintivos, espirituales y materiales, intelectuales y afectivos que caracterizan a una sociedad o un grupo social. Este engloba, además de las artes y las letras, los modos de vida, los derechos fundamentales al ser humano, los sistemas de 
valores, las tradiciones y las creencias y que la cultura da al hombre la capacidad de reflexionar sobre sí mismo (pág. 11).

En continuación a lo antes expuesto se puede decir que hace de nosotros seres específicamente humanos, racionales, críticos y éticamente comprometidos por medio de discernimiento de los valores y efectuando opciones para la toma conciencia de sí mismo, se puede decir que los petroglifos son el patrimonio tangible la expresión de la cultura en las grandes realizaciones materiales.

\subsection{Antecedentes de la Investigación}

Por medio de los antecedentes se realiza una síntesis conceptual de trabajos realizados, a continuación, se hace referencia a los siguientes trabajos de investigación, ya que guardan estrecha relación con el presente estudio. En primer lugar, Obispo, Hurtado, Santana, Contreras y Jiménez (2007), describen a estas esculturas de la siguiente manera: "Petroglifos las Lajitas y Bum-Bum Estado Barinas interpretaciones en el tiempo" (pág. 2); se puede acotar que esta investigación tiene como objetivo estudiar las interpretaciones atribuidas a las estaciones rupestres de Bum-Bum y las Lajitas del estado Barinas, así como al mítico cerro de Peña Viva, en el tiempo presente y en el tiempo pasado.

Esta investigación se centra en el método etnográfico, este es, el estudio descriptivo de la cultura de una comunidad o de algún aspecto, en una perspectiva global y trabajo de campo que plantea el método se realiza por medio de la observación participante, con el propósito de tener un acercamiento a la realidad que se pretende estudiar.

En este sentido, García (2007): "estrategias educativas para la valoración del patrimonio cultural en la educación básica en Venezuela" (pág. 1); para ello, se analizaron los diseños curriculares de este nivel educativo y su relación con el patrimonio cultural. El resultado de esta revisión permitió 
identificar contenidos y objetivos ya existentes en el currículo que permiten utilizar los bienes culturales locales como recursos para el desarrollo de proyectos pedagógicos.

Además, aquí se plantean estrategias educativas para así valorar el patrimonio cultural, inculcando el conocimiento adecuado a los estudiantes de Educación básica, en relación con la presente investigación se da a entender que es necesario implantar estrategias didácticas educativas que permitan a los estudiantes obtener un aprendizaje significativo, estas estrategias planteadas por el autor, serán necesarias para la adquisición de nuevos conocimientos esto permite al estudiante conocer y conservar el patrimonio cultural, por ende, nos lleva a pensar en planificar factibles acciones de mantenimiento y la valoración de su importancia.

\subsection{Bases Legales}

El Estado moderno en sus políticas, que involucran al colectivo de la sociedad para el logro de sus objetivos, requiere partir de una base legal que sustente sus propósitos. Venezuela como país soberano ajusta sus metas y objetivos a un marco legal. Por ende, se fundamenta en los instrumentos jurídicos que especifican el deber ser y el Derecho a la Educación, la cultura y la tecnología.

A través de los cuerpos normativos y dispositivos más relevantes, como la Constitución Nacional de la República Bolivariana de Venezuela (1999):

La creación cultural es libre. Esta libertad comprende el derecho a la inversión, producción y divulgación de la obra creativa, científica, tecnológica y humanista, incluyendo la protección legal de los derechos del autor o de la autora sobre sus obras. El Estado reconocerá y protegerá la propiedad intelectual sobre las obras científicas, literarias artísticas, inversiones innovaciones, denominaciones, patentes, marcas y lemas de acuerdo con las condiciones y excepciones que establezca. La ley y los tratados internacionales suscritos y ratificados por la República esta materia (art. 98). 
Ciertamente la cultura está comprendida por dichos factores donde se observa el derecho a la inversión, producción y divulgación de la obra creativa, cabe destacar que el derecho del autor sobre sus obras es de gran importancia, el estado reconocerá y protegerá la propiedad intelectual sobre las obras culturales ya sean científicas, literarias, artísticas. Así mismo, la cultura interpreta el ámbito social en diferentes actos como anteriormente se plantearon:

Los valores de la cultura constituyen un bien irrenunciable del pueblo venezolano y un derecho fundamental que el Estado fomentará y garantizará, procurando las condiciones, instrumentos legales, medios y presupuestos necesarios. Se reconoce la autonomía de la administración cultural públicas en los términos que establezca la ley (art 99).

El Estado garantizará la protección y preservación, enriquecimiento, conservación y restauración del patrimonio cultural tangible e intangible, y la memoria histórica de la nación. Los bienes que constituyen el patrimonio cultural de la nación son inalienables, imprescriptibles e inembargables. La Ley establecerá las penas y sanciones para los daños causados a estos bienes (art. 99).

De esta forma describimos cultura como valores que son fundamentales para una sociedad como lo es Venezuela ya que el patrimonio cultural en dicha ley indica la protección, preservación, conservación de sí mismo. Establece que existen penas y sanciones para los daños causados de estos bienes.

\section{Metodología}

En la investigación- acción, el quehacer científico consiste no sólo en la compresión de los aspectos de la realidad existente, sino también en la identificación de las fuerzas sociales y las relaciones que están detrás de la experiencia humana. Ofrece otras ventajas derivadas de la práctica misma, ya que permite la generación de nuevos conocimientos al investigador y a los grupos involucrados, la movilización y el reforzamiento de las organizaciones 
y finalmente, el mejor empleo de los recursos disponibles en base al análisis crítico de las necesidades y las opciones de cambio. Los resultados se prueban en la realidad elaborando orientaciones para los procesos de acción o las modificaciones de los procesos precedentes.

Por su parte, Moser y Ornauer (1978): señala que la investigaciónacción. Se basa en cuestiones de mejora y cambio social. Uno de sus objetivos principales es aclarar las intenciones de la gente que actúa y analizar las relaciones de comunicación y las estructuras sociales a partir de sus acciones. Se trata de conocer la forma en que la gente interpreta las estructuras sociales para desarrollar actividades comunes, a través de sus organizaciones. La concientización es una idea central y meta en la investigación-acción, tanto en la producción de conocimientos como en las experiencias concretas de acción.

En relación al carácter descriptivo, Ary (2004): expone en su libro Introducción a la Investigación Pedagógica que ello "comprende la descripción, registro, análisis, observación e interpretación de la realidad objeto de estudio" (pág. 12).

En consecuencia, el estudio está enmarcado en la investigación descriptiva la cual comprende la descripción, registro, análisis e interpretación de la naturaleza actual, y la composición o proceso de los fenómenos. Es importante acotar que esta posición se hace sobre conclusiones dominantes, sobre grupo de personas o cosas.

Mediante este trabajo de investigación se desea lograr un cambio de conducta en los pobladores de Bum-Bum, Ubicados en el Municipio Antonio José de Sucre del Estado Barinas hacia la conservación de los petroglifos, para elaborar acciones didácticas o sencillamente para fomentar valores y actitudes para Concienciar a los pobladores de Bum-Bum sobre la Conservación del Área donde se Encuentran Petroglifos.

En este sentido, en la presente investigación se recurrió a la metodología cualitativa-interpretativa, la cual se utiliza para estudiar cómo las 
personas ven, entienden y construyen su mundo, de acuerdo a lo expresado por Palella y Martins (2010): al respecto, los métodos cualitativos han despertado un interés creciente, debido a los diferentes marcos epistemológicos para conceptuar la naturaleza del conocimiento de la realidad social y los procedimientos para captar estos fenómenos.

En la actualidad, los métodos cualitativos de investigación gozan de prestigio y experimentan una gran popularidad, pero hasta hace poco es sitio de pertenecía única y exclusivamente al positivismo científico norteamericano y a la medición cuantitativa.

En resumen, la investigación cualitativa valora las perspectivas de los investigados sobre sus mundos y busca descubrir esas perspectivas; requiere la inmersión del investigador en la vida cotidiana de su objeto de estudio; visualiza la investigación como un proceso interactivo entre el investigador y el investigado; y es principalmente descriptiva y depende de las palabras y los comportamientos de las personas como fuente de datos primarios (Marshall y Rossman, 1989).

\section{Resultados}

De acuerdo a las experiencias vividas en la realización de esta investigación, se pudo llegar a la conclusión de que es importante y necesario que el tema de conservación de los petroglifos sea abordado en las diferentes poblaciones que se encuentren ubicadas estos grabados del país, haciendo especial énfasis en la conciencia de conservación, con la finalidad de logar en los pobladores la sensibilidad ante la conservación de su patrimonio cultural.

Es importante mencionar la educación es un proceso de formación que ha evolucionado al pasar de los años en el ámbito institucional y académico, en tal sentido, en su laboriosa tarea de crear un sistema adaptado a las circunstancias que rodean al hombre y lo condicionen de manera que mantenga una conducta acorde a la sociedad, la Educación ha experimentado 
diversas teorías y corrientes pedagógicas que intentan solucionar en la mejor medida los problemas y necesidades tanto cognitivas como psicológicas del individuo.

Para continuar se recomienda la ejecución de investigación ya que se considera como una experiencia significativa debido a que despertara en los investigadores una sensibilidad y preocupación especial por los recursos naturales y patrimonio cultural, ya que la inadecuada utilización de los mismos podría llevar a un caos en el ecosistema y pertenencia de nuestra cultura.

\section{Referencias}

Ary, R. (2004). Introducción a la investigación pedagógica. México: Editorial interamericana.

Bonell, H. (2005). Los petroglifos como formas de comunicación simbólica reportaje investigativo. Universidad de los Andes Dr. Pedro Rincón Gutiérrez Departamento Comunicación Social. Táchira, Venezuela. Recuperado de:

http://servidor-opsu.tach.ula.ve/tesis acro/gn799 p4b6/bonell h.pdf

Constitución Nacional de la República Bolivariana de Venezuela (1999). Artículo $N^{\circ}$ 98. Venezuela.

Criollo y Rojas (1995). Petroglifos en Venezuela. Museo de Arte de Caracas, Venezuela. Recuperado de: http://petroglifos.ve.tripod.com

Fernández, G., y Guzmán, A. (2013). El patrimonio histórico-cultural revalorizado en el marco de un desarrollo sustentable del turismo. Argentina. [Documento en línea]. Recuperado de:

http://webcache.googleusercontent.com/search?q=cache:http://www.e quiponaya.com.ar/turismo/congreso/ponencias/aldo ramos.htm\&gws $\underline{\mathrm{rd}=\mathrm{cr} \& \mathrm{ei}=\mathrm{FFoHWJfhGMW} 9 \mathrm{edX} 3 \mathrm{sPgO}}$ 
García, Z. (2007). Estrategias educativas para la valoración del patrimonio cultural en la educación básica en Venezuela. Universidad de los Andes.

Infopedia Barinas (2007a). Patrimonio Arqueológico del municipio Antonio José de Sucre. Versión ALFA. Barinas, Venezuela. Recuperado de: http://www.barinas.net.ve/infopedia/ARTICULOM-210-

Patrimonio Arqueologico del municipio Antonio Jose de Sucre-2630.htm

Infopedia Barinas (2007b). Orígenes de Bum Bum ¡Tierra mágica! en el municipio Antonio José de Sucre. Versión ALFA. Barinas, Venezuela. Recuperado de:

http://www.barinas.net.ve/infopedia/ARTICULOM-161-

Origenes de Bum Bum Tierra magica en el municipio Antonio Jo se de Sucre-26-25.htm

Marshall, C., \& Rossman, G. (1989). Designing qualitative research. Newbury Park, CA: Sage.

Moser, H., y Ornauer, H. (Eds.) (1978). Internationale Aspekte der Aktionsforschung. München. Kösel Verlag.

Obispo, M., Hurtado, L., Santana, V., Contreras, M., y Jiménez, J. (2007). Arte Rupestre del Estado Barinas, Venezuela. [Documento en línea]. Recuperado de: http://petroglifos6.blogspot.com

Palella y Martins (2010). Investigación cuantitativa. Universidad Yacambu.

Tylor, E. (1975). "La ciencia de la cultura", a KAHN, J.S. (comp.): El concepto de cultura: textos fundamentales, p. 29-46. Barcelona: Anagrama.

UNESCO (2011). Patrimonio cultural Un Enfoque Diverso y Comprometido. México, D.F. Recuperado de:

http://www.unesco.org/new/fileadmin/MULTIMEDIA/FIELD/Mexico/pdf/ $\underline{\text { CIRO seguridad p.pdf }}$ 


\section{Livia Elizabeth Arista Díaz \\ e-mail: livieliza@hotmail.com}

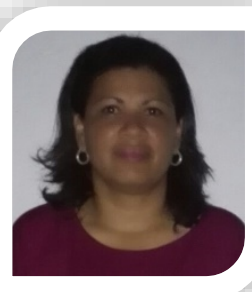

Nacida en Barinas Estado Barinas, Venezuela. Cursa estudio de maestría en educación ambiente y desarrollo en Universidad Pedagógica Experimental Libertador, núcleo Barinas. Profesora en Educación Integral en la UPEL, Barinas. T.S.U. Educación Mención Integral. Con participación en II Jornada de Educación Inicial, Taller "Orientaciones Técnicas Metodológicas para la producción de soluciones Educativas Computarizadas, Curso uso Educativo de las tecnologías de la información y la comunicación, Curso de Linux Versión KNOPPIX 3.7, Producciones Pedagógicas, I Feria Edumática, II Feria Edumática, III Feria Edumática, Curso de Capacitación Docente, Facilitadora de Servicios Comunitario de la Urbanización Llano Alto, Jornada: Practicas Practicantes y Producción Pedagógica ,I Curso de Auxilios Médicos de Emergencia, Proyecto Pedagógico de Aula y I Congreso estadal de la calidad Educativa. Actualmente se desempeña como profesora en Liceo Nacional Bolivariano José Félix Ribas del Estado Barinas.

El contenido de este manuscrito se difunde bajo una Licencia de Creative Commons ReconocimientoNoComercial-Compartirlgual 4.0 Internacional 